\title{
ПОВЫШЕНИЕ ЭФФЕКТИВНОСТИ ПРОЕКТИРОВАНИЯ РАЗРАБОТКИ НОВОГО ГАЗОКОНДЕНСАТНОГО АКТИВА МЕТОДАМИ ИНТЕГРИРОВАННОГО МОДЕЛИРОВАНИЯ
}

\author{
Зипир Владислав Геннадьевич1, \\ ZipirVG@inbox.ru \\ Чернова Оксана Сергеевна 1 , \\ ChernovaOS@hw.tpu.ru \\ 1 Национальный исследовательский Томский политехнический университет, \\ Россия, 634050, г. Томск, пр. Ленина, 30.
}

\begin{abstract}
Актуальность исследования обусловлена необходимостью использования комплексного подхода по интегрированному моделированию при проектировании разработки новых газоконденсатных активов Крайнего севера. На сегодняшний день в России наблюдается устойчивая тенденция разработки месторождений в пределах Арктических регионов Западно-Сибирской нефттегазоносной провинции. Добывающие компании, работающие в пределах этой территории, рассматривают запасы углеводородного сырья Крайнего севера как перспективный вариант для компенсации падения добычи в ближайшем будущем. Стратегическое планирование процесса разработки является первостепенной задачей, которую трудно выполнить на высоком уровне без применения современных подходов по математическому моделированию. При разработке таких активов цена ошибки кратно возрастает в связи с высокими геологическими, технологическими и экономическими рисками. Поэтому в работе детально рассмотрен подход по интегрированному проектированию разработки газоконденсатных активов с применением интегрированной модели как ключевого элемента, позволяющего повысить точность стратегического планирования.

Цель: доказать эфффрективность от применения интегрированного моделирования при проектировании разработки автономных газоконденсатных месторождений Крайнего севера.

объект: новые неразрабатываемые газоконденсатные активы Крайнего севера.

Методы: индивидуальный подход при моделировании процесса добычи и подготовки углеводородного сырья, интегрированное моделирование процесса разработки газоконденсатных месторождений Крайнего севера.

Результаты. Разработана этапность расчетов на интегрированной модели при проектировании разработки газоконденсатных активов Крайнего севера. Описан индивидуальный подход к применению моделей добычи и подготовки углеводородного сырья. Доказана эфрфективность от применения интегрированной модели.
\end{abstract}

\section{Ключевье слова:}

Стратегическое планирование, газоконденсатное месторождение, оптимизация процесса добьчи, проектирование разработки, интегрированная модель.

\section{Введение}

Период разработки «легких» и доступных газоконденсатных месторождений закончился. Сегодня в России наблюдается устойчивая тенденция разработки активов в пределах Арктических регионов Западно-Сибирской нефтегазоносной провинции. Добывающие компании, работающие в пределах этой территории, рассматривают запасы углеводородного сырья Крайнего севера как перспективный вариант для компенсации падения добычи в ближайшем будущем. Однако методики, применяемые при проектировании разработки автономных газоконденсатных активов, значительно отличаются от общепринятых и могут повлечь серьезные технологические риски. Реализация долгосрочных проектов разработки удаленных от инфраструктуры месторождений, находящихся в сложных климатических и топографических условиях, диктует повышенные требования к процессу проектирования разработки. В основном это связано с необходимостью понимания детализированной концепции подготовки отдаленных активов к эксплуатации до начала выполнения рабочей документации и строительства [1].

Стратегическое планирование процесса разработки месторождения, а также оптимизация эксплуатационных и капитальных затрат являются первостепенными задачами, которые трудно выполнить на высоком технологическом уровне без применения современных методик математического моделирования - использованию комплексных численных моделей месторождения, объединяющих пласт, скважины, инфраструктуру и подготовку. По оценкам международных консалтинговых и аудиторских агентств более половины реализованных в последние годы нефтегазодобывающих проектов достигли более низкие технико-экономические показатели по сравнению с проектными. Расхождение запланированных и фактических показателей обусловлено следующими причинами:

- недостаток входной информации для точного проектирования на начальных этапах разработки проектной документации;

- применение упрощенных консервативных средств моделирования, вместо использования комплексных интегрированных моделей (ИМ) актива;

- низкая эффективность менеджмента рисков и неопределенностей на основании многовариантных оценок путей разработки актива с учетом скрининга и ранжирования мероприятий;

- человеческий фактор.

Ошибки, допущенные на начальных этапах проектирования месторождения, могут иметь существенные последствия, особенно для активов Крайнего севера. С учетом истощения ресурсных баз по газоконденсатным провинциям России, высокой стоимости применяемых технологии по добыче и подготовке углеводородного сырья, 
а также интенсивно меняющейся макроэкономической ситуации цена ошибки кратно возросла по отношению к периоду конца XX в. [2]. Недооценка стоимости объектов обустройства и подготовки или переоценка поставленных на баланс запасов углеводородного сырья может привести к значительному снижению чистого дисконтированного дохода и снижению рентабельности проекта.

Потребность точного планирования при решении столь масштабных долгосрочных задач привела к интенсивному развитию концепции интегрированного проектирования с учетом менеджмента рисков и неопределенностей. В результате интегрированное моделирование стало одним из ключевых и мощнейших инструментов при проектировании разработки месторождений. При этом наибольшего эффекта от применения интегрированного подхода на этапе выбора стратегии разработки газоконденсатного актива можно достичь в основном за счет экономии и оптимизации капитальных вложений.

Важным аспектом работ в районах Крайнего севера является определение способа доставки добываемого сырья до потребителя. Данный аспект оказывает значительное влияние на финансовое утяжеление проектов разработки автономных газоконденсатных активов в отдаленных районах. При условии транспорта добываемого сырья по магистральному трубопроводу до точки сдачи возможно включение данного участка системы в качестве отдельной модели для расчета гидравлических потерь. При условии транспортировки добываемого сырья морским путем расчет рентабельности проекта выполняется исходя из стоимости транспортировки сырья на уровне экономической модели.

На сегодняшний день развитые Российские и Зарубежные нефтегазовые компании успешно применяют интегрированное проектирование на стадии планирования разработки актива [3]. Например, концерн «Шелл» использует концепцию интегрированного проектирования как неотъемлемую часть системы Smart Field для моделирования многовариантных сценариев развития актива, что позволяет повысить коэффициент извлечения нефти, снизить капитальные затраты, а также оптимизировать производственные процессы. В ПАО «ЛУКОЙЛ» активно внедряется в деятельность ценных нефтегазодобывающих активов система по автоматизированному управлению интегрированными моделями (АСУПИМ). Данная система позволяет автоматизировать и упростить работу с интегрированными моделями, что приводит к оптимизации трудозатрат и повышению эффективности планирования. В ПАО «НК «Роснефть» при применении интегрированного подхода используется разработанный корпоративный программный продукт РН-КИН.

Разработка активов Крайнего севера имеет особые требования, которые в обязательном порядке должны быть учтены при проектировании:

1. Суровые климатические условия Крайнего севера накладывают существенные ограничения на процесс разработки автономных газоконденсатных месторождений. При обустройстве месторождения выбор оборудования для эксплуатации объектов связан непосредственно с условиями окружающей среды. Например, способ прокладки и тип изолирующего покрытия трубопроводов системы сбора влияет на температурный режим эксплуатации и, как результат, на степень риска образования гидратных пробок в системе транспортировки газа [4]. Температура окружающей среды в летний и зимний период определяет необходимость выбора многофункциональных систем подготовки газа и газового конденсата, способных обеспечивать качественную подготовку углеводородного сырья при высоких температурах в летний период и низких температурах в зимний период. Также необходимо заблаговременно планировать и подбирать технику, способную обеспечивать геофизические, гидродинамические и газоконденсатные исследования на скважинах, а также различные геолого-технические мероприятия в условиях низких температур.

2. Охрана окружающей среды. К сегменту по охране окружающей среды применяются особые требования при разработке активов Крайнего севера, где наблюдается повышенная степень экологической опасности. Также важно учитывать, что большинство рассматриваемых территорий принадлежат коренным народам Крайнего севера, что значительно повышает степень ответственности добывающих компаний.

3. Существенные капитальные вложения и операционные затраты. В основном стоимость капитальных и операционных затрат определяется отдаленностью актива от промышленных центров, стоимостью бурения скважин, их заканчивания и обустройства месторождения, включая требования по качественной подготовке углеводородного сырья. Необходимость строительства протяженных трубопроводов для транспортировки углеводородного сырья с учетом регламентирующих требований также значительно утяжеляет проекты на разработку отдаленных газоконденсатных месторождений. Поэтому оптимизации капитальных и операционных затрат является многовариантной задачей, которая не может быть решена за счет применения классических подходов.

4. Процесс разработки активов Крайнего севера подразумевает наличие значительных геологических, технологических и экономических рисков. По этой причине большая часть месторождений до сих пор не вовлечена в активную разработку и остается необустроенной. Основной причиной является отсутствие коммуникаций и постоянно действующих подъездных путей. Добывающим компаниям приходится тщательно планировать процесс подготовки, транспортировки и сдачи углеводородного сырья на удаленные локации, что в свою очередь значительно утяжеляет проекты на разработку месторождений [5].

5. Использование передовых технологий. Количество пробуренных скважин и способ их заканчивания вносят весомый вклад в утяжеление проектов на разработку месторождения. Территории Крайнего севера сильно заболочены, что делает трудоемким процесс отсыпки кустовых площадок для бурения скважин и строительство подъездных путей. Для корректного проектирования необходимо проводить многовариантные анализы с использованием экономической модели для выбора оптимального количества добывающих скважин с учетом достижения требуемого коэффициента извлечения газа и газового конденсата. Передовые технологии в области бурения позволяют сократить капитальные затраты за счет применения 
скважин с большими отходами от вертикали, горизонтальных а также многозабойных скважин. Внедрение новых технологий в одной области оказывает существенное влияние на всю систему добычи в целом [6]. Поэтому при проектировании разработки месторождения важно рассматривать каждый узел системы, начиная от скважин и заканчивая объектами подготовки и транспортировки углеводородного сырья, как предмет оптимизации за счет внедрения передовых технологий.

Прежде чем дойти до потребителя, углеводородное сырье проделывает серьезный путь, начиная от движения в виде молекул по поровым каналам в пласте, по стволу скважины, системе сбора продукции, проходя при этом различные ограничивающие и регулирующие устройства и заканчивая системой подготовки, где происходит полное преобразование и сепарация добытой продукции до целевых ориентиров. Данные процессы протекают согласно закону сохранения энергии и массовому балансу [7]. Все части технологической цепочки взаимосвязаны и изменение любого параметра или компонента отражается на работе всей системы. Особенно сильно взаимовлияние систем прослеживается при эксплуатации газоконденсатных месторождений, где процесс добычи и транспортировки осуществляется за счет энергии пласта без применения насосно-компрессорного оборудования. В этом случае изменение технологического режима одной скважины моментально отражается на эксплуатационных параметрах соседних скважин, подключенных к единой системе сбора. Однако создание типовых проектов разработки заключается в выполнении последовательных расчетов. В различных программных продуктах строятся отдельные модели для воспроизведения течения флюида в пласте, скважинах, системе сбора, модели площадочных объектов, а также производится расчет экономических показателей проекта [8]. Процессом моделирования занимаются специалисты различных узконаправленных дисциплин с периодическим взаимодействием между собой, что не позволяет выполнить сопряженные расчеты всех систем разработки и добычи и учесть влияние между ними. Как правило, расчеты на модели пласта проводятся без учета наземного обустройства, а подбор системы наземного обустройства выполняется без учета оказываемых ограничений на потенциал пласта, что в конечном итоге не позволяет определить оптимальную систему разработки месторождения и приводит к значительным погрешностям при стратегическом планировании. При подобном подходе полностью отсутствует возможность оценить влияние одних показателей систем на другие и на экономическую эффективность проекта.

В результате эффективные и согласованные решения могут быть приняты только при совместном рассмотрении всех элементов, оказывающих влияние на технологические и экономические показатели разработки актива. Максимальной эффективности можно достичь только с использованием комплексного подхода и применения интегрированного моделирования на стадии принятия проектных решений.

\section{Интегрированное моделирование}

Интегрированное моделирование - процесс, который позволяет объединить все ключевые дисциплины проекта (геология, разработка, бурение, добыча, обустройство месторождения, подготовка продукции, экономика, анализ рисков) за счет комплексной модели с целью повышения эффективности бизнес-планирования процесса разработки и эксплуатации месторождения. Изначально интегрированный подход зародился при освоении шельфовых проектов, где применяются менее гибкие с точки зрения реконструкции системы, а цена ошибки при проектировании и стратегическом планировании может быть катастрофически высокой. Интегрированное моделирование позволяет убрать разобщенность при расчетах процессов движения флюида в пласте, скважинах, системе сбора и системе подготовки за счет применения единого интегрированного инструмента для расчетов. Полномасштабная ИМ газового актива включает в себя следующие компоненты: гидродинамическая модель пласта (ГДМ), модель добывающих скважин (МДС), модель системы сбора (МСС), модель площадочных объектов (МПО), а также экономическая модель (рисунок). Во главе рассмотренных моделей стоит интегрирующий комплекс, который позволяет специалистам проводить расчеты на связке из моделей с учетом взаимовлияния всех систем и заданных ограничений [9]. При этом в каждой приведенной модели при гидравлических расчетах используется заранее построенная PVT-модель флюида, которая может использоваться в качестве упрощенной модели «черной нефти», либо полноценной композиционной модели.

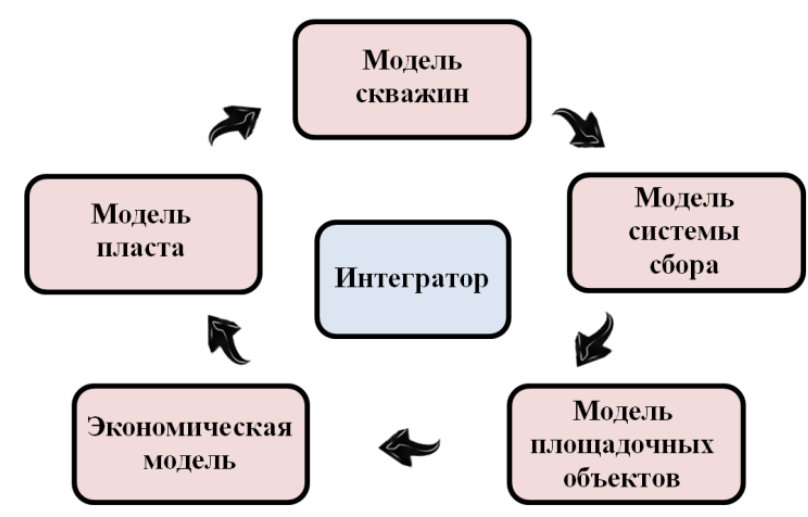

Рисунок. Состав интегрированной модели

Figure. Integrated model components

Перед тем как приступить к построению ИМ, необходимо определиться с целевыми ориентирами и задачами. Несмотря на то, что интегрированный подход однозначно обладает преимуществом перед традиционными методиками расчета, необходимо оценить, насколько достигнутые положительные эффекты компенсируют затраты на создание ИМ, так как создание качественной ИМ требует гораздо больших временных и трудовых затрат, чем работа с отдельными моделями. Также построение ИМ требует особого отношения к качеству и полноте исходных данных, так как погрешность при настройке одной модели-компонента будет вносить систематическую ошибку в расчет всей модели.

Основная цель применения ИМ на этапе проектирования заключается в определении оптимальной стратегии разработки газоконденсатного актива на основе многова- 
риантных расчетов с учетом запланированных ограничений и взаимовлияния всех систем, участвующих в процессе добычи, подготовки и транспортировки газа и газового конденсата.

Сформулированы основные задачи, которые необходимо выполнить на стадии проектирования разработки месторождения методами интегрированного моделирования:

- подбор оптимальной системы разработки месторождения, обеспечивающей максимальные коэффициенты извлечения газа и газового конденсата в долгосрочной перспективе;

- определение очередности ввода, конструкций и глубинного оборудования добывающих скважин, обеспечивающего эффективную эксплуатацию газоконденсатного фонда с учетом изменяющихся термобарических условий в процессе разработки месторождения;

- выбор оптимального типа системы сбора газа на основе проведения многовариантных расчетов с учетом загрузки шлейфов на разных стадиях эксплуатации актива, а также с учетом изменяющихся термобарических условий транспортировки;

- расчет этапности ввода объектов подготовки и компримирования на основании перспективных объемов добываемой продукции и входного давления на установку подготовки;

- учет взаимовлияния смежных объектов разработки либо газоконденсатных месторождений при условии совместной эксплуатации;

- стратегическое планирование объемов добычи газа и газового конденсата в долгосрочной перспективе с учетом этапности ввода смежных объектов разработки и соседних месторождений.

\section{Междисциплинарный подход}

Эффективность интегрированного моделирования актива во многом зависит от степени внедрения междисциплинарного подхода на предприятии. При стандартном подходе инженер гидродинамик строит модель пласта, например, для прогнозирования снижения пластового давления со временем и оценки количества конденсата, выпавшего из газа в процессе разработки. Инженер по добыче выполняет расчеты на модели скважин и системы сбора, чтобы определить, как при изменении режима работы добывающих скважин изменяются потери давления по системе. Инженер по подготовке, в свою очередь, выполняет расчеты по оценке качества подготовки газа при изменении входного давления на установку. Все три инженера работают с разными расчетными инструментами, чтобы решить единую задачу, при этом делая определенные предположения и допущения. Интегрированное моделирование позволяет убрать разобщенность при расчетах процессов движения флюида в пласте, скважинах, системе сбора и системе подготовки за счет применения единого интегрированного инструмента для расчетов.

Важно, чтобы инженер по интегрированному моделированию обладал знаниям по всем дисциплинам, задействованным в расчетах. Например, проводя расчеты на модели скважин и системы сбора, нужно понимать, как производится замер и интерпретация гидродинамических и газоконденсатных исследований, чтобы определить, откуда берутся погрешности в расчете и как их устранить [10]. При подключении к расчету модели площадочных объектов необходимо понимать устройство и чувствительность каждого элемента, задействованного в расчете. Комплексность знаний инженера, занимающегося расчетами, позволит избежать ошибок, которые могут стать критическими при проектировании разработки месторождения.

Однако, несмотря на степень компетенций инженера по интегрированному моделированию, для всех процессов должна быть предусмотрена система независимой экспертной оценки с участием опытных специалистов всех задействованных служб. Это повысит степень ответственности за операции на интегрированной модели, а также согласованность и точность всей модели. Также будет очень ценно, если эксперты помимо знаний технологических процессов будут обладать опытом в области построения моделей и проведения имитационных расчетов.

\section{Компоненты интегрированной модели}

Рациональность применения, определяющаяся временными и трудовыми затратами на содержание ИМ, вызывает необходимость использования единой модели для выполнения краткосрочных и долгосрочных расчетов [11]. Для конкретных случаев данное условие не может быть выполнено в силу функциональных особенностей. Например, при необходимости моделирования и настройки 1000 скважин сложность ИМ кратно возрастает. В подобных случаях рациональным путем будет введение определенных допущений касательно точности настройки модели и подхода по моделированию большого количества скважин. Поэтому важно определить и смоделировать ключевые физические процессы, которые будут максимально влиять на точность и прогнозную способность предполагаемой модели. Далее предлагается рассмотреть исходные данные, необходимые для настройки моделей компонентов.

1. PVT модель пластового флюида.

PVT модель флюида - это физико-химическая модель, описывающая свойства и поведение пластового флюида с изменением условий среды, в которой он находится [12]. Это единственная модель, которая в определенной форме задействована в расчетах каждого компонента ИМ (модель пласта, скважин, системы сбора и подготовки). Точность задания модели флюида напрямую влияет на погрешность проводимых расчетов, прогнозную способность ИМ и скорость проводимых расчетов. Важно детально подходить к каждому компоненту системы и выбирать между использованием композиционной модели флюида либо модели «черной нефти» в зависимости от решаемых задач.

Например, применение композиционной модели флюида для модели добывающих скважин и системы сбора позволит определить количество ингибитора, необходимое для безгидратной эксплуатации при различных термобарических условиях. В данном случае важно провести точный расчет потерь давления по системе, отследить выпадение жидкостной составляющей из газовой смеси. Однако при проведении стратегических рас- 
четов важно применять подход по упрощению модели добывающих скважин и системы сбора с использованием модели «черной нефти» для увеличения скорости расчета модели.

Использование композиционной модели флюида для гидродинамической модели пласта рационально при решении узких задач, которые, как правило, выполняются с использованием только модели пласта без дополнительных связок. Однако значительное увеличение длительности расчета вызывает необходимость применения модели «черной нефти», вместо композиционной модели при работе с гидродинамической моделью пласта в связке с ИМ [13]. Выбор подходящей модели флюида для каждого компонента ИМ является очень важным аспектом, определяющим качество и трудоемкость проводимых расчетов.

\section{2. Модель пласта.}

При стратегическом планировании можно использовать два типа модели пласта: гидродинамическую модель пласта и модель материального баланса. Наиболее распространенным и точным способом оценки изменения состояния залежи в процессе эксплуатации, а также прогнозирования истощения пласта является использование ГДМ. Цифровая ГДМ - это сложная математическая модель, представляющая собой систему дифференциальных уравнений, для решения которых используются численные методы конечно-разностного представления производных. Для новых месторождений модель пласта позволяет проводить анализы различных вариантов разработки (определение оптимального количества скважин, системы разработки, а также способа эксплуатации залежи), рассчитывать ожидаемую добычу и экономическую эффективность проекта [14]. Для действующих месторождений модель пласта позволяет проводить текущий мониторинг выработки залежи, а также вносить корректировки в режим эксплуатации фонда скважин. ГДМ строится на основе геологической модели пласта, которая дополнительно наделяется динамическими характеристиками. Прогнозная способность фильтрационной модели зависит от качества её построения и адаптации на существующий набор исторических данных. Как правило, при первичной адаптации ГДМ претерпевает большое количество изменений и корректировок, так как моделирование несет в себе много неопределенностей, которые постепенно уходят в процессе эксплуатации и разбуривания месторождения.

Метод материального баланса - это базовый объемный баланс, учитывающий изменение пластового давления в динамике с учетом установленных отборов газа. Методика дает адекватные результаты лишь для залежей, представленных хорошо выраженными, непрерывистыми коллекторами. Однако при оценке сложно построенных линзовидных залежей, разбитых на многочисленные тектонические блоки, применение метода материального баланса зачастую дает низкую сходимость фактических и прогнозных данных. Важно отметить, что методика применяется в основном для определения среднего пластового давления залежи с учетом текущих отборов. При применении метода объемного баланса для расчета давления в зоне дренирования скважин возникает большое количество неопределенностей. Метод материального баланса рационально использовать для действующего месторождения с накопленной историей разработки, что позволит провести адекватную адаптацию модели. Однако при проектировании разработки нового газоконденсатного месторождения применение модели материального баланса не рекомендуется, так как модель может выдавать значительные погрешности при долгосрочных прогнозах.

3. Модель добывающих скважин.

МДС позволяет воспроизвести течение флюида от забоя к устью с учетом всех существующих ограничений. Для моделирования скважины необходимы следующие входные данные:

- инклинометрия;

- конструкция скважины;

- заканчивание скважины;

- лифтовое оборудование;

- геотермальный градиент пласта;

- теплопроводность стенки скважины.

При проектировании разработки нового актива необходимо использовать проектные конструкции скважин. Для подбора глубины спуска и диаметра насоснокомпрессорных труб (НКТ) необходимо провести дополнительные расчеты для определения оптимальных потерь давления по лифту. Также важно, чтобы диаметр НКТ обеспечивал необходимую скорость потока для выноса жидкой фазы с забоя скважин, так как это позволит избежать проблем при эксплуатации [15].

4. Модель системы сбора

МСС позволяет воспроизвести течение флюида от скважин до установки подготовки с учетом изменяющихся термобарических условий. Для построения МСС необходимо задать следующие параметры:

- длина трубопровода;

- диаметр трубопровода;

- толщина стенки;

- шероховатость;

- профиль трассы;

- способ прокладки и тип изоляции;

- теплопроводность системы;

- температура окружающей среды.

Для проектирования нового газоконденсатного месторождения необходимо использовать многовариантный подход для выбора оптимального типа системы сбора. Для этого создается несколько МСС с учетом различного расположения и подключения кустовых площадок [16]. При проведении расчетов на интегрированной модели выбирается оптимальный тип системы сбора, учитывающий параметры эксплуатации газопровода при изменяющейся загрузке на различных стадиях разработки месторождения. Система сбора должна обеспечивать оптимальную скорость течения газа для выноса жидкой фазы с низинных участков с учетом минимальных потерь давления по системе.

5. Модель площадочных объектов.

Процесс подготовки продукции на газовых и газоконденсатных месторождениях имеет ряд особенностей, которые позволяет учесть детально построенная МПО. Режим работы объектов подготовки накладывает ограничения на работу добывающего фонда, так как для качественной подготовки газа, которая зачастую осуществляется за счет перепада давления при низкотемпературной 
сепарации, необходимо поддерживать минимальное давление на входе в установку. Также любая установка комплексной подготовки газа имеет свою собственную гидравлическую характеристику, зависящую от входного давления, количества поступающего газа, конденсата и воды. Важно понимать, что уровень добычи газа и конденсата, получаемый при расчете на ГДМ пласта выводится в условиях одноступенчатой сепарации. Объем газа и конденсата одноступенчатой сепарации всегда ниже, чем при многоступенчатой сеперации, и недоучет этого может привести к расчетам искаженных показателей добычи. Поэтому при стратегических расчетах на интегрированной модели важно использовать МПО с применением композиционной модели флюида.

Еще одним фактором является то, что при снижении пластового давления значительная часть выпавшего конденсата остается в пласте. В результате во входном потоке на объекты подготовки растет концентрация легких фракций $(\mathrm{Cl}-\mathrm{C} 4)$ и падает концентрация более тяжелых (C5+) компонентов [17]. Применение МПО позволит учесть данный фактор при планировании уровней добычи.

\section{Этапность расчетов при проектировании разработки актива}

Для каждой задачи необходимо применение ИМ разной детализации и степени упрощения [18]. Эффективность расчетов заключается в поиске компромисса между точностью расчета и быстродействием модели. При этом ИМ различной степени детализации могут использоваться для различных типов расчетов и существовать независимо друг от друга. Однако, чтобы достичь качественного результата, необходимо понимать теорию, физику процессов и узкие места с учетом реалии разработки месторождения. Это понимание будет влиять на принятие того или иного решения по упрощению. Помимо повышения степени практичности, упрощение модели также полезно в случаях, когда входных данных для построения и адаптации модели слишком мало, что особенно заметно при построении ИМ для проектирования разработки новых активов. Поэтому при необходимости концептуального выбора между большим количеством рассчитанных вариантов приветствуется упрощение модели. Это позволит повысить количество выполняемых расчетов и сократить время на проведение операций. Важно выполнять расчеты на единой ИМ для сравнения полученных вариантов в одинаковых условиях. Оптимальные варианты в дальнейшем будут пересчитаны на полноценной детализированной модели для выбора конечного сценария разработки.

При проектировании разработки нового газоконденсатного актива данных для создания точных моделей недостаточно. В этом случае используются проектные данные, корректность которых оценивается при проведении многовариантных расчетов [19]. Далее предлагается рассмотреть этапность построения интегрированной модели:

1. Создание PVT-модели флюида. На данном этапе необходимо создать композиционную модель флюида на основе имеющихся газоконденсатных исследований в разведочных скважинах, а также в скважинах, пробуренных при опытно промышленных работах. Данная модель является основой и используется во всех компонентах, включенных в состав ИМ место- рождения. Построенная модель флюида используется для создания модели «черной нефти», которая будет использоваться для упрощения ИМ.

2. Создание модели пласта. Модель материального баланса не обладает достаточной точностью при проведении долгосрочных прогнозов на стадии проектирования разработки месторождения. Поэтому для данной задачи рекомендуется использовать гидродинамическую модель пласта, которая настраивается на результаты испытаний разведочных скважин, а также скважин, пробуренных при опытно-промышленных работах. Композиционная модель в составе ГДМ используется для решения узконаправленных задач и значительно утяжеляет расчет на ИМ. Поэтому при проведении долгосрочных расчетов необходимо использовать модель «черной нефти».

3. Создание моделей скважин. Для каждого типа проектных скважин (наклонно-направленная, с горизонтальным окончанием, ОРЭ и др.) необходимо создать шаблонную модель, конструкция и профиль которой будут максимально приближены к реалиям разработки. Для повышения точности расчета рекомендуется использовать композиционную модель флюида. В прогнозных расчетах построенные модели скважин будут использоваться в виде VFP таблиц на уровне ГДМ пласта для ускорения расчетов.

4. Создание модели системы сбора. Необходимо создать несколько типов моделей, на основе которых при проведении долгосрочных расчетов будет выбрана оптимальная модель системы сбора. Данная модель должна обеспечивать оптимальные потери давления в системе с учетом различных термобарических условий и изменяющейся загруженности трубопроводов в процесс разработки месторождения. В процессе проведения расчетов диаметры секций могут изменяться для достижения максимальной эффективности эксплуатации системы сбора.

5. Создание модели площадочных объектов. Необходимо создать упрощенную модель установки комплексной подготовки газа (УКПГ) на основании проектных представлений для учета перепада давления, требуемого для подготовки добываемой продукции [20]. МПО будет являться последним звеном ИМ, определяющим режим эксплуатации газоконденсатного фонда.

Следующим шагом после построения ИМ является поэтапное выполнения расчетов, которые позволят определить максимально эффективную стратегию разработки актива:

1. Подбор диаметра и глубины спуска НКТ для проектных скважин. Данный расчет позволит подойти индивидуально к каждой скважине за счет подбора глубинного оборудования, обеспечивающего достаточную скорость течения газа для выноса жидкой фазы забоя скважин, а также оптимальные потери давления с учетом планируемого режима работы проектных скважин.

2. Подбор оптимального графика ввода проектных скважин с учетом загруженности системы сбора. Требуется предусмотреть равномерный ввод добывающих скважин, чтобы избежать проблем с образованием гидратных и жидкостных пробок в системе сбора на ранней стадии эксплуатации месторождения. 
3. Проведение долгосрочных расчетов на ИМ с подключением заранее созданных моделей системы сбора. Для точного сравнительного анализа все расчеты должны быть выполнены в идентичных условиях. Необходимо оценить загрузку шлейфов на разных стадиях эксплуатации месторождения и выбрать оптимальный тип системы сбора для дальнейших расчетов на ИМ.

4. Первая итерация стратегических расчетов на интегрированной модели в составе: ГДМ (модель «черной нефти»), МДС (модель «черной нефти»/композиционная модель), МСС (модель «черной нефти»/композиционная модель), МПО (композиционная модель). Для упрощения ИМ и ускорения долгосрочных расчетов допускается использование модели флюида «черной нефти» для МДС и МСС, при этом необходимо предварительно проверить достаточную сходимость с композиционной моделью, сделав один пробный расчет в одних условиях. Также рекомендуется перевести модель скважин в формат VFP кривых для задания модели скважин на уровне ГДМ. Данное упрощение позволит осуществить связку ИМ на устье скважин и рассчитать тренд падения буферного давления по каждой скважине. Первая итерация долгосрочных расчетов необходима для оценки потенциала пласта без учета ограничения по входному давлению на УКПГ. Полученные на ИМ уровни добычи газа и конденсата позволят определить этапность ввода дожимной компрессорной станции для проведения расчетов, более близких к реальным условиям эксплуатации газоконденсатного актива, за счет энергии пласта.

5. Вторая итерация стратегических расчетов. На данном этапе важно задать ограничение по минимальному входному давлению на площадочные объекты для возможности транспортировки подготовленной продукции до завода либо пункта сдачи продукции. При этом важно корректно определить этапность снижения входного давления, на основе которого будет подбирать компрессорное оборудование. Задаваемые ограничения позволят учесть взаимовлияние всех элементов системы добычи при расчете на ИМ и по-

\section{СПИСОК ЛИТЕРАТУРЫ}

1. Guyaguler B., Ghorayeb K. Integrated optimization of field development, planning, and operation // Society of Petroleum Engineers. - 2006. - № 102557. - P. 1-13.

2. Ahmed T., McKinney P.D. Advanced reservoir engineering. Burlington: Elsevier, 2005. - P. 187-286.

3. Toby S. Making the best of integrated asset modeling // Society of Petroleum Engineers. - 2014. - № 171161. - P. 1-11.

4. Adaptive approach to integrated modeling of development an exploitation of group of gas-condensate fields with a single production gathering and processing system / P.V. Vinogradov, E.A. Sadreev, E.R. Nugumanov, E.I. Sergeev, A.A. Gimazov // Society of Petroleum Engineers. - 2015. - № 176583. - P. 1-23.

5. Povyishev K., Vershinin S., Vernikovskaya O. Specifics of development, infrastructure construction and production of oil-gascondensate fields. Integrated model application experience // Society of Petroleum Engineers. - 2017. - № 187857. - P. 1-11.

6. Optimization of operation of the system reservoir-well-pipeline-GTU based on the integrated modeling / S. Bikbulatov, A. Smirnov, V. Buleiko, I. Mukminov, S. Romashkin // Society of Petroleum Engineers. - 2014. - № 171220. - P. 1-15. лучить прогнозные уровни добычи по месторождению в долгосрочной перспективе.

Последовательное выполнение всех перечисленных операций позволит учесть ограничения смежных систем при проектировании разработки газоконденсатного актива и спрогнозировать стратегию разработки месторождения с учетом реалий эксплуатации газоконденсатных залежей, где процесс добычи и транспортировки пластового флюида происходит за счет энергии пласта. Детально спроектированная модель площадочных объектов позволит получить реальные расходы товарного газа, воды и конденсата с учетом процессов многоступенчатой сепарации при различных температурах и давлениях.

\section{Заключение}

Подходы, применяемые при проектировании разработки автономных газоконденсатных месторождений, значительно отличаются от общепринятых и определяются высокими геологическими, технологическими и экономическими рисками. Стратегическое планирование процесса разработки месторождения является первостепенной задачей, которую трудно выполнить на высоком уровне без применения современных подходов по математическому моделированию. Ошибки, допущенные на начальных этапах проектирования месторождения, могут иметь существенные последствия. В свою очередь интегрированное проектирование на сегодняшний день стало одним из мощнейших инструментов для решения инженерных и инвестиционных задач, которые стоят перед нефтегазовой отраслью. Поэтому в работе детально рассмотрен подход по интегрированному проектированию разработки газоконденсатных активов с применением ИМ как ключевого элемента при стратегическом планировании. Выбор оптимальной системы разработки месторождения очень важен для проектирования разработки автономных газоконденсатных активов Крайнего севера, где цена ошибки при планировании катастрофически высока и может повлечь серьезные экономические риски. Составленный алгоритм проектирования разработки газоконденсатного месторождения на ИМ позволит повысить эффективность и снизить риски при стратегическом планировании.

7. Dake L.P. Fundamentals of reservoir engineering. - Burlington: Elsevier, 1998. - P. 1-42.

8. The features of building the integrated model for development of two gas-condensate formations of Urengoyskoe field / A. Ignatyev, S. Bikbulatov, I. Mukminov, S. Romashkin, S. Buchinskiy, E. Vikulova // Society of Petroleum Engineers. - 2013. - № 166892. P. 1-18.

9. Зипир В.Г. Базовые принципы построения интегрированной модели разрабатываемого месторождения углеводородов // Проблемы разработки месторождений углеводородных и рудных полезных ископаемых: Материалы X Всероссийской научнотехнической конференции. - Пермь, 2017. - С. 142-145.

10. Crompton J., Gilman H. The future of integrated operations // Society of Petroleum Engineers. - 2011. - № 127715. - P. 1-7.

11. Integrated asset modeling in West Siberia: a case study / D.A. Batalov, R.Y. Yusupov, M.A. Zykov, V.G. Zipir, D.P. Gontarev, V. Kukushkin, R. Bayguzov, E. Kraynova, M. Krivokorytova, A. Kharkovsky // Society of Petroleum Engineers. - 2018. - № 192578. - P. 1-7.

12. William D., McCain Jr. The properties of Petroleum Fluids. Oklahoma: PennWellBooks, 1989. - P. 147-164.

13. Bartolomeu M.J., Abdrakhmanov A.B. Integrated production modelling of gas condensate field // Society of Petroleum Engineers. - 2014. - № 171453. - P. 1-18. 
14. Kyrnaev D.V. RITEK starts to develop an intelligent field approach // Oil.Gas.Innovations. - 2015. - № 1. - P. 62-63.

15. Зипир В.Г. Эксплуатация газоконденсатных месторождений в условиях самозадавливания добывающего фонда // Проблемы геологии и освоения недр: Труды XXIII Международного научного симпозиума имени академика М.А. Усова студентов и молодых ученых. - Томск, 2019. - Т. І. - С. 105-107.

16. Ghoraeb K., Holmes J.A., Torrens R. Field planning using integrated surface/sub surface modeling // Society of Petroleum Engineers. 2005. - № 92381. - P. 1-9.

17. Закиров С.Н. Разработка газовых и газоконденсатных месторождений. - М.: Недра, 1998. -628 с.

18. Coupling of a surface network with reservoir simulation / A. Kosmala, S.I. Aanonsen, A. Gajraj, V. Biran, K. Brusdal, A. Stokkenes,
R. Torrens // Society of Petroleum Engineers. - 2003. - № 84220. P. $1-11$.

19. Integrated modeling as an instrument for unique gas condensate field development concept choice / T.I. Gataullin, A.V. Poushev, A.V. Prokopenko, A.V. Sullagaev // Society of Petroleum Engineers. - 2017. - № 187794. - P. 1-14.

20. Howell A., Torrens R., Szatny M. From reservoir through process, from today to tomorrow - the integrated asset model // Society of Petroleum Engineers. - 2006. - № 99469. - P. 1-20.

Поступила: 03.10.2019.

\section{Информация об авторах}

Зипир В.Г., аспирант отделения геологии, разведки и разработки полезных ископаемых Инженерной школы природных ресурсов Национального исследовательского Томского политехнического университета.

Чернова О.С., доктор геолого-минералогических наук, ведущий эксперт Центра подготовки и переподготовки специалистов нефтегазового дела Национального исследовательского Томского политехнического университета. 
UDC 622.279.23:622.279.51

\title{
IMPROVEMENT OF EFFICIENCY OF DEVELOPING GREEN GAS-CONDENSATE FIELD PROJECT USING INTEGRATED ASSET MODELLING
}

\author{
Vladislav G. Zipir ${ }^{1}$, \\ ZipirVG@inbox.ru \\ Oksana S. Chernova ${ }^{1}$, \\ ChernovaOS@hw.tpu.ru \\ 1 National Research Tomsk Polytechnic University, \\ 30, Lenin avenue, Tomsk, 634050, Russia.
}

The relevance of the research is caused by the necessity to apply the integrated asset modeling to develop the project of green gas-condensate fields located in Extreme North regions. Today steady trend of hydrocarbon field development located in Arctic region of West-Siberian petroleum province is observed in Russia. Operating companies in this location consider the hydrocarbon reserves of Extreme North regions as the potential for compensation of production decrease in the very near future. Development of such fields is the priority task that is difficult to fix without leading simulation approaches. Development of self-contained fields is not standard business because of high geological, technological and economical risks. It requires complex approaches for development and high-quality staff as the investment outlay responsibility is too high. That is why the integrated asset modeling is considered as the basement for project development.

The main aim of the study is to prove the value of the integrated asset modeling for project development of self-contained green gas-condensate fields located in Extreme North regions.

Objects: green gas-condensate fields of Extreme North regions.

Methods: customized approach for modeling the production and treatment operation, integrated modeling of gas-condensate fields located in Extreme North regions.

Results. Stage-by-stage approach of the integrated asset modeling is designed for developing the project of green gas-condensate fields of Extreme North regions. The paper considers the customized approach for application of production and treatment models. The efficiency of the integrated asset modeling is proved.

\section{Key words:}

Long-range planning, gas-condensate field, production process optimization, field project development, integrated model.

\section{REFERENCES}

1. Guyaguler B., Ghorayeb K. Integrated optimization of field development, planning, and operation. Society of Petroleum Engineers, 2006, no. 102557, pp. 1-13.

2. Ahmed T., McKinney P.D. Advanced reservoir engineering. Burlington, Elsevier Publ., 2005. pp. 187-286.

3. Toby S. Making the best of Integrated asset modeling. Society of Petroleum Engineers, 2014, no. 171161, pp. 1-11.

4. Vinogradov P.V., Sadreev E.A., Nugumanov E.R., Sergeev E.I. Gimazov A.A. Adaptive approach to integrated modeling of development and exploitation of group of gas-condensate fields with a single production gathering and processing system. Society of Petroleum Engineers, 2015, no. 176583, pp. 1-23.

5. Povyishev K., Vershinin S., Vernikovskaya O. Specifics of development, infrastructure construction and production of oil-gascondensate fields. Integrated Model Application Experience. Society of Petroleum Engineers, 2017, no. 187857, pp. 1-11.

6. Bikbulatov S., Smirnov A., Buleiko V., Mukminov I., Romashkin S Optimization of operation of the system reservoir-well-pipeline-GTU based on the integrated modeling. Society of Petroleum Engineers 2014, no. 171220, pp. 1-15.

7. Dake L.P. Fundamentals of reservoir engineering. Burlington, Elsevier Publ., 1998. pp. 1-42.

8. Ignatyev A., Bikbulatov S., Mukminov I., Romashkin S., Buchinskiy S Vikulova E. The features of building the integrated model for development of two gas-condensate formations of Urengoyskoe field. Society of Petroleum Engineers, 2013, no. 166892, pp. 1-18.

9. Zipir V.G. Bazovye printsipy postroeniya integrirovannoy modeli razrabatyvaemogo mestorozhdeniya uglevodorodov [Base aspects of hydrocarbon field integrated modeling]. Problemy razrabotk mestorozhdeniy uglevodorodnykh i rudnykh poleznykh iskopaemykh Materialy X Vserossiyskoy nauchno-tekhnicheskoy konferentsi [Hydrocarbon and ore mineral fields exploitation problems. Materials of X Russian national Science and Technology Conference]. Perm, 2017. pp. $142-145$

10. Crompton J., Gilman H. The future of integrated operations. Society of Petroleum Engineers, 2011, no. 127715, pp. 1-7.
11. Batalov D.A., Yusupov R.Y., Zykov M.A., Zipir V.G., Gontarev D.P., Kukushkin V., Bayguzov R., Kraynova E., Krivokorytova M., Kharkovsky A. Integrated asset modeling in West Siberia: a case study. Society of Petroleum Engineers, 2018, no. 192578, pp. 1-7.

12. William D., McCain Jr. The properties of petroleum fluids. Oklahoma, PennWellBooks Publ., 1989. pp. 147-164.

13. Bartolomeu M.J., Abdrakhmanov A.B. Integrated production modelling of gas condensate field. Society of Petroleum Engineers, 2014, no. 171453 , pp. $1-18$

14. Kyrnaev D.V. RITEK starts to develop an intelligent field approach. Oil.Gas.Innovations, 2015, no. 1, pp. 62-63.

15. Zipir V.G. Ekspluatatsiya gazokondensatnykh mestorozhdeniy v usloviyakh samozadavlivaniya dobyvayushchego fonda [Exploitation of gas-condensate fields with production wells liquid loading problem]. Problemy geologii $i$ osvoeniya nedr. Trudy XXII Mezhdunarodnogo nauchnogo simpoziuma imeni akademika M.A. Usova studentov i molodykh uchenykh [Problems of geology and subsoil development. Materials of the XXIII International Scientific Symposium of Academic M.A. Usov of students and young scientists]. Tomsk, 2019. Vol. 1, pp. 105-107.

16. Ghoraeb K., Holmes J.A., Torrens R. Field planning using integrated surface/sub surface modeling. Society of Petroleum Engineers, 2005, no. 92381 , pp. 1-9.

17. Zakirov S.N. Razrabotka gazovykh $i$ gazokondensatnykh mestorozhdeniy [Gas and gas-condensate field exploitation]. Moscow, Nedra Publ., 1998. 628 p.

18. Kosmala A., Aanonsen S. I., Gajraj A., Biran V., Brusdal K., Stokkenes A., Torrens R. Coupling of a surface network with reservoir simulation. Society of Petroleum Engineers, 2003, no. 84220, pp. 1-11.

19. Gataullin T.I., Poushev A.V., Prokopenko A.V., Sullagaev A.V. Integrated modeling as an instrument for unique gas condensate field development concept choice. Society of Petroleum Engineers, 2017, no. 187794 , pp. $1-14$

20. Howell A., Torrens R., Szatny M. From reservoir through process, from today to tomorrow - the integrated asset model. Society of Petroleum Engineers, 2006, no. 99469, pp. 1-20. 
Information about the authors

Vladislav G. Zipir, postgraduate student, National Research Tomsk Polytechnic University.

Oksana S. Chernova, Dr. Sc., leading expert, National Research Tomsk Polytechnic University. 